UDC 811.111:81'373.72

DOI: $10.17223 / 24109266 / 12 / 2$

\title{
PLACE NAMES METAPHORA IN LANGUAGE AND COMMUNICATION
}

\author{
T.V. Khvesko
}

\begin{abstract}
Teaching universal cultural concepts in the system of intercultural education is considered to be an effective means of a foreign language knowledge improving. The relationship of Place names with personal names, vocabulary words, landscape terms, archaic Indo-European roots, language and communication are considered in complex with history and cultural impact. The correlation of mental images with linguistic verbalisation of Place names is observed. Special attention is paid to the nominator creativeness when metaphorical transfer of mental spaces occurs in Place names. The cognitive approach to a foreign language teaching through universal intercultural concepts is offered.
\end{abstract}

Keywords: nomination; creativeness; metaphor; universal; local features; Place names; culture; morphology; nickname; concept.

\section{Aims and methods}

The aim of the article is to explore the relationship between cognitive concepts and cultural concepts as embodied in metaphorical, figurative Place names and to show universal and local features of Place names having metaphorical associations in different cultures. The practical aim is to show how teaching of universal cultural concepts in the System of intercultural education effects foreign language knowledge. Ethnic conflicts in European countries have raised a question whether the ideas of multiculturalism appeared to be a failure or not. Some people are ready to deny the principles of multicultural education. We do not offer radical changes, but certainly new ideas should be taken into consideration. The challenges of globalization appeal to develop a new theoretical approach within intercultural education. It is well known that native speakers unconsciously transfer their cultural values to a foreign language for international communication use. It leads to mutual misunderstanding. How do we help the students to prevent such a situation? To create effective intercultural invironment for the students a new approach is offered. General methodology is based on the idea of cultural interaction in a multicultural society and the necessity of acquisition not only of a language system, but also a conceptual system in the process of foreign language teaching.

The following linguistic methods were used in our research: 1) investigation of universal cultural concepts due to the dictionaries description, etymological, morphological and structural analysis of Place names in Rus- 
sian and English; 2) investigation of micro contexts containing some characteristics of a particular concept in a broad contexts (phraseological units, idioms).

\section{Introduction}

We try to demonstrate that cognitive metaphors are instantiations of cultural categories manifested in the language spoken by the community that shares a common set of characteristics within a given cultural matrix. Following Lakoff and Johnson [1], Kövecses [2] considers that metaphors classified in cognitive categories account for cultural categories, both in terms of conceptual universals and variants, resulting in a complex mapping of interrelated cross-connections. "According to the cognitive linguistic theory, one concept is represented in our mind by a series of other concepts that together constitute a coherent whole, in the form of a mental frame. However, there are social and cultural, even ideological concepts that are hardly generalizable, and hence, not universal" [3].

As analyzed by Zoltan Kövecses [4], an example may be the representation of the self, which is variable across different cultures. In Western societies that emphasise the self, the concept of Place name is associated with the Personal name of the owner of destination. Cognitive presentation of reality is observed in Place Names which reveal some general classes: those embodying personal names, chiefly the surnames of pioneers or of national heroes; those transferred from other and older places, either in the eastern states or in Europe; Indian, Dutch, Spanish, French, German and Scandinavian names; Biblical and mythological names; names descriptive of localities; and names suggested by the local flora, fauna or geology [5]. The names of the first class are perhaps the most numerous. Some consist of surnames standing alone, as Washington, Cleveland, Bismarck, Lafayette, Taylor and Randolph; others are contrived of given names, either alone or in combination, as Louisville, St. Paul, Elizabeth, Johnstown, Charlotte, Williamsburg and Marysville. The number of towns in the United States bearing women's given names is enormous. Most of these places are small, but there is an Elizabeth with 75,000 population, an Elmira with 40,000, and an $A u$ gusta with nearly 45,000 . We divide all the nominations into primary and secondary. The first one means direct correlation of the name with its object in mind, while the second type of name giving is metaphorical. Generalization is clearly seen in nicknames, e.g.: Alwine bierd (1148) $\rightarrow$ BEARD; Robert le Bor (1287) $\rightarrow$ BOAR; John Baron (1296) $\rightarrow$ BARON, BARRON; Uluricus Wilde (1086), Henry le Wylde (1236) $\rightarrow$ WILD.

The appearance of a person is manifested in the Personal names: Henry Bigge (1177), Thomas Blac (1198), John le Brade (1212), Geoffrey Bunch (1195), Hugh Crees (1316), Richard Fatt (1260), William Short 
(1327), COPPER NOSE. Professional activity is manifested in the names: William le Bakere (1177), Robert le Carpenter (1212), William the Floutere (1268), Humphery le Hunte (1203), Richard le Scrivien (1208-13).

Our investigations concentrate on Place names and historical development of culture. We try to show universality and variation in the linguistic expression of metaphora across various cultures. Some Place names are very matter-of-fact about natural surroundings: Twin Lakes (in six states), Three Lakes (in two states) and even Mosquito Lake (just in Alaska). Dinosaur, Colorado also falls into this what-you-see category. Sometimes, American Place names draw on natural features that are not merely seen with the eyes, but also perceived by the nose and the tongue, maybe the well water tasted like diluted candy (Sweetwater), maybe something in the air smelled like rotten eggs (White Sulphur Springs) [5].

It is interesting to note that many towns were named after tastes people prefer in their diets. Americans are obviously inspired by sugar and salt, but have little regard for spiciness. There is only one Spiceland in Indiana. Salt tops sugar in popularity, especially if you count towns named Saline or Salineville (six of them) or Salinas (just one in California). There are numerous cities with names that advertise their supposed wealth in coal, lumber, wheat, corn, towns named Enterprise and the much rarer towns named Success. There are plenty of Place names that seem eager to flaunt wealth and status.

The meanings of topographical terms can vary a good deal from name to name, for some elements used over a long period in the formation of English Place names underwent considerable changes of meaning during medieval times: Old English feld originally "open land" developed a later sense "enclosed plot", Old English wald "forest" came to mean "open upland", and Old English leah "wood" became "woodland clearing" and then "meadow", Godmaer's $\rightarrow$ Gomers, Grimesthorpe, Grimsto [6].

The choice of the most likely meaning for one of these elements in an individual name is therefore a matter of judgement, based among other things on locality, the nature of the compound, and assumptions about the age of the name. Moreover recent research has increasingly shown that what seem to be similar terms for hills or valleys, woodland or marshland, or agricultural land had fine distinctions of meaning in early times. Different Old English terms for "hill" like dun, hyll, hrycg, hoh, heafod, and ofer are far from being synonymous, seem to have had their own specialized meanings. In addition these and other common topographical elements like eg (island), hamm (enclosure), and halh (nook) were each capable of a wide range of extended meanings according to date, region, and the character of the landscape itself [7]. Place names form very large and diverse groups, representing description of some topographical objects either natural or man-made, which were then transferred to the settlement, in which some components are used metaphorically: Crowborough, Glastonbury, Neasden, Greenock, 
Brightlingsea, Orcney, Bourton-in-the-Water, Bourton-upon-Trent, Bourton-in-the-Hill, Black Bourton, Burton Constable, Clayton-le Moors, Clayton-le-Dale, Clayton-le-Wools.

The names for rivers and streams, springs and lakes, fords and roads, marshes and moots, hills and valleys, woods and clearings, and various other landscape features are also the names of inhabited places: Sherborne, Fulbrook, Bakewell, Tranmere, Oxford, Breamore, Stodmarsh, Swindon, Goodwood - all have the second element that denote topographical features.

\section{Compositional structure of Place names}

Place names, its functioning, meaning and origin, structure and the area of distribution, historical development and semantical changes, the relationship of names and vocabulary words are studied in various cultures [8-11]. Place name response to the sociological changes is immediate so they can serve as chronological units as well. Ancient Indo-European elements are presented in place-names being an informational source. Place name scholars collect spellings of Place names (including the names of old places that have been lost) from charters, court records and other ancient documents. The names of small places can be especially important in studying family names of local origin: some families took their name, not from a village but from an individual house in which they lived, e.g. Blakeway or Copplestone [12].

Culture, history, geography and linguistic analytical methods have found successful application in Place names studies. The origin and borrowings of geographical names are considered to deal with cultural heredity. We suppose the variability of the linguistic forms of Place names is caused by the history of the country, whether it describes some topographical objects either natural or man-made, which were then transferred to the settlement: Bourton-in-the-Water; object quality: Leeds Castle; Gidea Park; Chidwell; or historical occasions: Brentwood; Barnstaple, Brittas Bay (briotas).

Place names research including cultural and sociological aspects, is an applied autonomous discipline, which observes cultural heredity of the society. The traditions of name giving are specific in each culture. It is closely connected with the history of the country: personal names and nicknames, place of birth and living, land owning, family relations, culture and labour $[7,13]$. Individual creative features of the Place names giving are considered in complex: mental cognition and cultural effect [14]. Interrelation of languages in the conditions of ethnic contacts initiates existence of territorial universal units, which participate in word compositions. Special attention in our research is paid to singling out universal and local features of Place names. Scientists try to reconstruct archaic forms and Indo-European roots which are saved in modern Place names [6, 15-17]. Some Indo-European roots being the parts of British Place names are used metaphorically: 
- Bel in Belfast, Belleek, Ballyshannon, Belcoo

- Boil in Newbottle, Newbattle, Bootle

- Burn in Bruton, Brockworth, Broxbourne, Kilburn

- Caer in Caernarvon, Carlile, Carstairs, Carn, Carnedd, Carnlea, Carron

- Cluain in Clinycracken, Clane, Cloncaird, Clunes, Clonmel

- Ey in Lambay, Dalkey, Ireland's Eye, Lundy, Walney

- Glas(s) in Glaslough, Kilmaglush, Glashaboy, Douglas, Glasnevin

- Grian in Grianan, Greenane, Clogrennan, Greenoge

- Lann in Lampeter, Lamlash

- Mark in Marbury, Merkbury, March, Marchmont

- Muir in Connemara, Kenmare, Murree, Glamorgan, Morecambe, Murrey.

Indo-European roots are the most informative components of the Place names [6]. Their analysis allows to find out the most ancient IndoEuropean borrowings (Murrey, Diskir, Derry) saved in old Slovenic languages $[10,15]$. Many old Place names have undergone some degree of reduction in the long period since they were first coined.

Most English Place names consist of two elements, the first of which usually qualifies the second. The first element in such compounds may be a river-name, a personal name, elements describing flora and fauna. The second element is a landscape term. Typical examples of metaphorical Place names being formed during the Old English period are: Daventry, Coventry, Oswestry, Dafas tre, Cofas tre, where tre means "the place of a hundred meeting" while in the following Place names different kinds of flora are presented by means of der / beith / ash:

Dar / der: Derwent, Daren't, Dart, Darly, Darvel (celtic: deruenta $\rightarrow$ dar / der); beith (Gaelic: beither $\rightarrow$ E birch): Dalbeattie; ash: Knotty Ash etc.

However some place-names consist of one element only, at least to begin with: examples include names like Combe ('the valley'), Hale, Lea, Stoke, Stowe, Thorpe, Worth, and Wyke. Less common are the names consisting of three elements such as Claverton (burdock ford farmstead), Redmarley, Woodmansterne, and Wotherton; in most of these the third element has probably been added later to an already existing compound [6] and showed linguistic creativeness of Place Names giving in the UK. There are kinds of Place names composition, one of the most frequent being the use of the medial connective particle -ing in Paddington, probably best explained as estate associated with a man called Padda. Some compound Place names in the western parts of England (especially in Cornwall, Wales, and Cumbria) have a different formation. They are so-called name-phrases in which the usual order of elements is reversed following Celtic practice: Aspatria (Patricks ashtree), Bewaldeth, Brigsteer, Landulph, and Tremaine. The names with this characteristic Celtic word-order are also predominant throughout Ireland, Wales and much of Scotland [8]. 


\section{Morphological processes as markers of a human creativity}

Linguistic creativeness as manifestation of nominator mental individuality is observed in morphological processes taking place in the original and borrowed Place names, it means they are universal.

We studied formation, development, scientific and folk interpretations of original and borrowed topographical onyms in diachrony and found universal and local features of Place names.

As mentioned above Place name is a universal phenomenon for the Indo-European languages. Linguistic creativeness as manifestation of nominator individuality is manifested in hybrid formings. Creative transformations of toponyms are clearly seen at the morphonological, lexical, and structural level of linguistic analysis. In British Place names the following morphological processes take place:

hybridization: Silverstone $\leftarrow$ Sewulf's + ton; Yelverton $\leftarrow$ Ellas + ford + ton; Glamorgan $\leftarrow$ glan + more + geni; Godmanchester $\leftarrow$ Lat. Godmund + cestre;

reduction: Fotheringhay $\leftarrow$ forth + here + ing + eg; Grantchester $\leftarrow$ Grant + set; Glen Affric $\leftarrow$ glen $+a+$ the + break;

reduplication: Torpenhow Hill $\leftarrow$ tor + pen + how + Hill;

adaptation: Conisbrough; Glastonbury; Gold's + pie $(E) \leftarrow$ by $(\mathrm{ON})$. Such modifications as stone $\rightarrow$ ton, borough $\rightarrow$ burg, chester $\rightarrow$ set cause the loss of primary meaning and appearance of naive folk interpretation of the new form, e.g. Brownsea Island $\rightarrow$ Brunkeseye, where the final component $E$ eye $\leftarrow O E$ ieg. Folk interpretation of Brownsee is considered: brown + sea.

In russian Place names the same morphological processes take place:

reduction: Semivragi, Prechistenka, Sukhodol, Sivtsev Vrajek, Kholmogory, Kitai-gorod, Spas-zaulki, Zamoskvorechie, Novgorod;

adaptation: Pinega, Onega, Ladoga, Vetluga, Sviyaga, Volga, Vichegda, Vologda, Nerekhta;

rotation: final component ga/da (means water) is observed in the North while in the centre of Russia va/ma is used: Neva, Sosva, Narva, Proshva, Kama, Chukhloma, Kostroma, Bogulma, Yakhloma; Tomsk.

hybridization: Belozero, Churozero, Ustozero, Orenburg, Omsk,

\section{Cognitive approach to metaphorical Place names}

Metaphora, its origin and some morphological processes concerning it can be observed in the Place name Manchester. The meaning is not chester of a man, but chester on the hills resembling breast of a woman (mamma). Metaphora is one of the basic mental operations in the process of getting 
knowledge, comparison and explaining the world around us. Everyday life, language, thinking and action - all this is metaphorical in nature. G. Lakoff and M. Johnson [1] concluded «the essence of metaphor is understanding and experiencing one kind of entity in terms of another kind». According to N.N. Boldyrev [18] cognitive linguistics is the science that deals with cognition in its linguistic reflection. Cognition, in turn, is a cognitive process in itself, and the result of this process is knowledge. Cognition is perception of the world, observation, estimation and categorization. One of the most important ideas of cognitive linguistics is that a concept defines the semantics of language meanings. Among the lexical resources that represent concepts in a language, we have identified the names composed by means of metaphor. We think that metaphor plays an important role in both the practical and theoretical thinking - the ability to show similarities between very different classes of objects. In other words, a human understands the unknown through the known, they understand abstract things through particular things. The notion can be transferred from one mental space to another [19].

Cognitive activity of a human is accompanied by the process of conceptualization, modern linguists believe it as "certain" cross-cutting for different forms of knowledge, particular minimal conceptual units. Concepts are the components of the human consciousness and knowledge of the world. The most important concepts are encoded in the language by means of morphological elements. A concept is a semantic formation marked by cultural features and in some way characterizing certain ethnic groups of people. The concept does not arise from the meaning of the word as a result of the dictionary definition, it is combined with personal and national experience of people.

"Conceptual metaphor is one of the most important cognitive mechanisms based on establishing links between concepts (conceptual framework), belonging to different fields of knowledge (domain)" [14]. Since metaphorization is based on associative connections within the human experience, the created metaphors borrow lexical means from the other spaces. Metaphoric process requires the target sphere (a new conceptual domain). While the source sphere is specific, the target sphere is abstract and is understood within the source sphere.

\section{Place names in communication}

Cognitive function of Place names is manifested in its ability to be part of such stable combinations as the London Eye, London smoke (in terms of the color of smoke); the lungs of London "squares and parks of London". Phraseological units include popular Place names: to turn out the best side to London; bet London to a brick "to be completely sure"; a London jury; hang half and save half "imperfect judicial system"; Lincoln was, London is, and 
York shall be "London is a thriving city"; Oxford for learning, London for wit, Hull for women, and York for a tit "London wit"; Oxford knives and London wives "London is fair of brides".

Place names containing information about the culture, traditions, public and political life of people, become a part of phraseological units. It becomes a kind of symbol containing cultural and historical information. Thus, in addition to identifying the object in space, the Place name in phraseological units performs symbolic and axiological functions, for example: Tom O'Bedlam means "crazy, insane". Now it is used in the meaning of extreme confusion and disorder (Bedlam $\rightarrow$ crazy house $\rightarrow$ mess). Phraseological units are stable word combinations, for which separation, semantic complication of components, morphological and syntactic fixation are characteristic. Such nicknames as "Golden-domed capital" are partially re-interpreted as phraseological units, because weakening of the initial meaning of the components accompanied by its transfer from one mental space to another according to the metonymic or metaphorical sign. We consider nomination to be primary or secondary ones, specifying that the primary nomination is the correlation of the name with the object of reality reflected in the mind. The secondary nomination is based on the use of units of language in metaphorical way. The popularization of the Place name leads to creation of nickname: American Rhine "the Hudson River". The image of Place name as a semantic duality, expressed in the transfer of the name from one space to another, is a generalized type of the verbal embodiment of the image, distinguished from a number of similar ones due to a significant feature [20].

The diversity of phraseological units in English is used to express the emotional response. It allows the speaker to express his attitude towards the object of evaluation, without identifying it. Conceptual modeling of phraseological semantics reveals root operation logical deduction based on the derivation of the conceptual mechanism updated memory available in personal and social knowledge. From the reflection point of view the basis of phraseological units with cultural knowledge are divided in the national cultural phraseological units and intercultural phraseological units, borrowed from other languages. The cultural sources of phraseological units with Place names are: historical events: meet one's Waterloo "fail"; Canterbury story "children's tale, fiction". Sources of intercultural phraseological units with Place names are: the biblical plagues of Egypt borrowing: Egyptian penalty "trouble, distress", the Tower of Babel "language barriers, noise", Sodom and Gomorrah; mythological borrowing: hot as Hades "extremely hot", black as Hades "joyless, bottomless", cross the Styx "die"; borrowing from other languages: do at Rome as the Romans do. The obvious predominance of cultural phrases clearly shows that the appearance of most of them is linked to social, economic, political and industrial activity. Less productive sources are lexical units concerning historical facts and events of the past. 
The bulk of the bibleonims and mifonims belong to universals, which are used not only in English but also in other languages. As a result of rethinking the shape is filled with new content: Adriatic tummy (Slang) "indigestion"; Havana rider "passenger who tries to hijack a plane". Research on the nature of the Place names as a component of phraseological units indicates that most of them are the names of popular settlements: to carry (send) owls to Athens, from Baltimore to San Francisco "very far away"; on (take) the road to Buenos Ayres (Slang) "become a prostitute"; the black hole of Calcutta "small, close and sweltering classrooms"; as poor as the Bishop of Chester "immensely rich"; as true as Coventry blue "reliable, stable"; enough to puzzle a Philadelphia lawyer "messy business"; all roads lead to Rome; better be the first in a village than second in Rome; the battle of Waterloo was won on the playing fields of Eton "glory England is forged in closed educational institutions" [21]. Analyzing phraseological units with Place names we tried to reveal universal and local peculiarities of Place names and find out how cultural concepts are imbodied in communication. Now we understand that the main feature of metaphora is deonimization of the Place names due to its communicative historical popularity, connected with social, economic, political and industrial activity [22, 23].

\section{Conclusion}

We came to the conclusion that the tradition of names giving is specific for each culture. Comparative analysis of the morphological structure of russian and english Place names helps to identify specific ethnic features realized in such morphological processes as reduction, reduplication, hybridization and adaptation. Due to globalization the structure of Place names is universal in both languages while local morphological content may vary because it is closely connected with cultural aspects, social norms of the society, conditions of people birth and living, lands owning, family relations and labor. Current tends of metaphoric names reflect cognitive mechanisms of concept transfer from one mental space to another, the correlation of universal communicative patterns with local linguistic verbalisation of cultural concepts. Special attention is paid to the nominator creativeness in the process of metaphorical transfer of mental or perceived images to Place names when cognitive mechanisms determine the morphological form of the Place names. The process of creativeness manifests not only the image of the landscape object but expresses the communicator selfrealization as well.

Personal names, Place names, nicknames as cultural concepts, play an important role in the process of communication. Globalisation presents a unique opportunity for currently new tends of the names giving with Internet communication expanding. The Place names show not only perception of reality (what-you-see or what you-feel) but help to create desired virtual 
nicknames. Specific features of Place names should be considered in complex with conceptualisation in definite culture. Practical application of the theoretical cognitive views challenge a new intercultural approach to the foreign language teaching. The process of a foreign language teaching should be based on the principles of cognitive sciences and focused on the fact that teaching foreign languages is not only a language code acquisition, but learning of the conceptual world picture of native speakers in comparison with the partner world picture. The idea of cultural conceptualization of Place names is topical. We realized how to teach students understand universal concepts. Communication competence development in the students paying particular attention to the universal cultural concepts, cultural differences and similarities of its interpretation in russian and english Place names help students to master high level of intercultural competence and prove the effectiveness of the new approach to a foreign language teaching.

\section{References}

1. Lakoff, G., Johnson, M.: Metaphors we live by. Chicago: University of Chicago Press (1980)

2. Kövecses, Z. Metaphor in Culture. Universality and Variation. Cambridge: Cambridge University Press (2005)

3. Popescu, T.: Business Metaphors: A case study of Peugeot advertisements in different languages. Journal of Linguistic and Intercultural Education - JoLIE 5. 109-124 (2012)

4. Kövecses, Z.: Where Metaphors Come from: Reconsidering context in metaphor. Oxford: Oxford University Press (2014)

5. Mencken, H.: The American Language. Bibliography. Surnames and Given Names. N. Y. 1156-1180 (1921)

6. Mills, A.: Oxford Dictionary of British Place Names. Oxford University Press. 427-513 (2003)

7. Cresswell, J.: Dictionary of First Names. Chambers Harrap Publishers, Edinburgh (2009)

8. Dorward, D.: Scotland's Place-Names. Glasgow: Bell and Bain Ltd. (2001)

9. Frolov, N.: Ethnic names avtochtons of Tyumen-Ob area in language cognition. Literature and culture in recent human knowledge. Tyumen: Tyumen State University. 243-270 (2005)

10. Golomidova, M.: Artificial nomination in Russian onomastics. Ekaterinburg: Ural State Pedagogical University (1998)

11. Khvesko, T. Interdisciplinary Approach to British Place Names Studies. Procedia - Social and Behavioral Sciences 154. 402-406 (2014)

12. Hanks, P., Hodges, F., Mills, A.D. et al.: The Oxford Names Companion: The Definite Guide to Surnames, Names and Place Names of the British Isles. Oxford University Press. YII-X (2002)

13. Delahunty, A.: Oxford Dictionary of Nicknames. Oxford University Press (2006)

14. Fauconnier, G.: Methods and Generalizations. Cognitive Linguistics, Foundations, Scope and Methodology. Berlin / N.Y. 95-124 (1999)

15. Khvesko, T. Common features of Russian and British Place names. International Journal of experimental Education 12. 76-77 (2013)

16. Mullonen, I.I.: Toponyms of Prisvirya (The problems of ethno-linguistical contacts). $\mathrm{PhD}$ Thesis. Petrozavodsk. 8-17 (2000) 
17. Murzaev, E.: Toponyms and geography. Russian Academy of Sciences, Institute of geography. Moscow: Nauka. 32-47 (1995)

18. Boldyrev, N.: Cognitive Semantics. Introduction into Cognitive Linguistics: course of lectures. Ed. 4-th. Tambov: Izdatelskiy Dom TGU im. G.R. Derzhavina. 22-35 (2014)

19. Alekseeva, L.M., Mishlanova, S.L., Isaeva E.V.: The Derivation Study of Metaphor. International Multidisciplinary Scientific Conferences on Social Sciences and Arts SGEM 2014. Antropology, Archeology, History and Philosiphy. Albena, Bulgaria. 217-225 (2014)

20. Kondakova, I.A.: Visual means containing toponyms in English. Abstract of Philology cand. dis. Kirov (2004)

21. Urazmetova, A.V.: English toponymy as a lexical subsystem of language (on the material of toponymic lexicon of Great Britain and the USA). Abstract of Philology doc. dis. Ufa (2016)

22. Kicherova, M.N., Efimova, G.Z., Khvesko, T.V.: Early Professional Socialization of University Students in Russia. Procedia - Social and Behavioral Sciences 200. 442-448 (2015)

23. Lakoff, G.: Embodied Mind, Embodied Philosophy. How the Science of Mind Changes Our Understanding of the World. The University of California at Berkeley (2001)

\section{Information about the author:}

Khvesko T.V. - Doctor of Philology, professor of the Department of Foreign languages, Tyumen State University (Tyumen, Russia). E-mail: khvesko@inbox.ru 